\title{
ANALYSIS OF DIFFERENTIAL ITEM FUNCTION (DIF) COATS-Haenszel USING DIFFERENT AREAS UNDER THE TOWN AND VILLAGE IN NATIONAL TEST DEVICE IN BANTEN IPA SD
}

\author{
Sukemi \\ STKIP PELITA PRATAMA Serang \\ soekemy@bantenkreatif.com
}

\begin{abstract}
Analysis of Differential Item Function (DIF) / otherness Function Item is an analysis conducted on a set of tests to determine the bias point. Bias grains occur because of differences in background of respondents test, while a good test devices have qualities of objectivity, transparency, accountability and non-discriminatory. This study aimed to describe the test items were contracted Differential Item Function (DIF) at the National Examination IPA SD devices based on differences in urban and rural areas in the province of Banten using Mantel-Haenszel statistical methods. Mantel Haenszel method is a statistical method that belong to the classical theory to estimate the capability (ability) answered correctly and one of the two groups Referring (City group) and Focus (village groups). In the analysis of the National Examination tests conducted by IPA $S D$ urban and rural areas because basically learning science provide insights into the learners to study the nature of life in a real and every region has a characteristic difference in the character of each. Learners tendency of characters to characters who occupied a very large area of influence, so that the DIF analysis was performed on the test device by city and village. The method used in this research is descriptive quantitative method based on the translation of factual data and systematically based on numerical analysis using statistics, with a population of primary school learners based on the classification of the city of Dan Village. Selection of the sample was done by using stratified random sampling by classifying and analyzing each unit of analysis. Data is collected using secondary data from relevant agencies and government agencies manually and online. The analysis carried out quantitative analysis using the Mantel-Haenszel method. The results of the analysis indicate that there Differential Item Function (DIF) on items of National Examination test devices based on the analysis of urban and rural differences. DIF infected grain on the test device, twelve grains of forty grains, with a tendency to point to areas of the city of five items and the tendency to rural areas totaled seven points. Data is collected using secondary data from relevant agencies and government agencies manually and online. The analysis carried out quantitative analysis using the Mantel-Haenszel method. The results of the analysis indicate that there Differential Item Function (DIF) on items of National Examination test devices based on the analysis of urban and rural differences. DIF infected grain on the test device, twelve grains of forty grains, with a tendency to point to areas of the city of five items and the tendency to rural areas totaled seven points. Data is collected using secondary data from relevant agencies and government agencies manually and online. The analysis carried out quantitative analysis using the Mantel-Haenszel method. The results of the analysis indicate that there Differential Item Function (DIF) on items of National Examination test devices based on the analysis of urban and rural differences. DIF infected grain on the test device, twelve grains of forty grains, with a tendency to point to areas of the city of five items and the tendency to rural areas totaled seven points. The results of the analysis indicate that there Differential Item Function (DIF) on items of National Examination test devices based on the analysis of urban and rural differences. DIF infected grain on the test device, twelve grains of forty grains, with a tendency to point to areas of the city of five items and the tendency to rural areas totaled seven points. The results of the analysis indicate that there Differential Item Function (DIF) on items of National Examination test devices based on the analysis of urban and rural differences. DIF infected grain on the test device, twelve grains of forty grains, with a tendency to point to areas of the city of five items and the tendency to rural areas totaled seven points.
\end{abstract}

Keywords : Differential Item Function (DIF), the National Examination IPA, Methods Mantel-Haenszel

Improved quality of learning as a benchmark learners in learning activities, becoming one of the important elements to know the learning process undertaken in developing the potential of learners. One aspect of education standards one of which is the assessment of the results of learners. Implementation of a national assessment of learning outcomes in Indonesia are set by Ministerial Regulation No.20 of 2007. Stating that: 
"Assessment of learning outcomes in primary and secondary education implemented by educators, educational and government units".

Implementation of educational assessment of primary school national examinations conducted by the educational unit or the so-called school exams under the coordination of the district / city, the ministry of religion, the provincial government and regional offices of the ministry of religion. National exam objectives according to Permendiknas No.20 of 2007 (1) as one condition of graduation of students from the education unit. (2) one of the considerations in the selection into the next education level. (3) for mapping quality coaching programs and educational units in order to improve the quality of education.

The device tests the national exam is one of the measurement process to the learning outcomes national level have an important role in the field of education. The evaluation results are given in the form of national examinations expected to be used to see the picture of the ability of learners in a genuine and serves as an indicator of the success of the educational process and is used to compare the quality of education between educational units and regions. Given the importance of the national exam, then the device is about compiled should really be able to measure what should be measured, providing reliable measurement results, and reflect the actual ability of learners. That is the difference scores obtained a learner with other learners solely because of differences in ability between them,

Prepare a test device involving the elementary school level exam $25 \%$ set by the ministry and $75 \%$ set by the government of the province. It is susceptible to bias affects the quality test on the test device. Theoretically national exam test device has been good because it has been analyzed by experts through subjective assessments of several experts and educators before diteskan devices, but the empirical quality of the test device has not been tested and analyzed quantitatively, therefore it is important to do the analysis. Quantitative analysis using the technique of classical test theory with Mantel Haenszel method. Mantel Haenszel method is a statistical methodestimation capability (ability) answered correctly and one of the two groups of R (City group) and F (village groups), The quality of a test that has a lower value of the information item causing the tests do not measure students' abilities objectively.

Learning science in primary schools is an initial basis for determining the quality of students proceed towards higher to understand the science, if the basis of assessment science in primary schools have not been able to measure what should be measured it will result in the quality of science at the next level will affect the quality of natural sciences next level.

Lesson IPA SD / MI aims to enable students have the following capabilities. 1) Gaining confidence in the greatness of the Almighty God by the presence, beauty and order of his creation, 2) Develop knowledge and understanding of the concepts of science that are useful and can be applied in everyday life, 3) Develop curiosity, attitudes positive and awareness of the existence of a relationship of mutual influence between science, environment, technology and society, 4) Develop a process skills to investigate the nature around, solve problems and make decisions, 5) Raise awareness to participate in maintaining, protecting and preserving the natural environment, 6) Raise awareness to appreciate nature and any regularity as a creation of God, 7) Acquire stock of knowledge, concepts and skills of science as a basis for continuing education to SMP / MTs. (BSNP, 2006). 
The process of science learning for oriented toward mastery of nature around the forming potential of learners based on the ability of knowledge on the environment. Ratings concept of science teaching in primary schools is not appropriate if the grain quality test device emphasizes on one hand the region. Acquisition of national test scores make a difference in the results of national examinations, the difference is due not to the competence of the students but these differences by differences in background beyond the competence such as gender, region and place of learning, causing injustice to the national exam results. Injustice scores on the national exam become an interesting phenomenon to study,

Quality device national exam IPA SD used must be of good quality if the device is the national exam are not objective, unjust, and impartially in providing information on exam results in different groups with the same ability, has a chance to answer correctly containing different nature of injustice in provide information on the grains. Therefore, the detection of the presence or absence of a national exam tests injustice properties necessary for losses on certain groups can be avoided and the ability of learners measured objectively. If at a test load grain in favor of a particular group, then the test is said to contain biases different in functionality grain or grain (Differential Item Function / DIF).

In detecting Differential Item Function (DIF) is basically done through comparison of the function of each item. Bias test occurs when all participants test capable of the same have different opportunities in answering correctly point the same test, or a test called unbiased if all participants test the ability equivalent gain the same scores on the items are homogeneous, and the proportion of participants correctly answer the same on every item test, When an item is relatively more difficult for groups that have cultural background and specific experience means that item bias. This item bias on a test result in discrimination or favoring certain groups that the cause may be viewed from various aspects, such as race (ethnicity), culture, region, gender, etc. (Osterlind, 1983, p. 179). Background differences that occur both in culture, race, sex on the learner a great effect on the quality of the resulting test device test device to be biased. Therefore the most important thing in anticipation minimalisirnya bias in the test device is to prepare experts and educators are competent high in order to get accurate test devices, so that the detection of the votes corresponding test results in providing the proper information.

Seeing the problems that arise with the quality of the test that contains ketidakobjektifan the researchers feel it is important to be examined as a research study. One factor that makes fretting on the test problems caused bias is a factor of regional differences, ie towns and villages.Based on the background of the problem then research institute, and give the title of this research is "Analysis of Differential Item Function (DIF) with Mantel-Haenszel method based Towns and Villages Regional Differences In Test Devices SD IPA National Examination in Banten".

\section{METHODS}

The study design is a procedure to collect data, analyze and report the results. So the study design is used to refer to the researchers plan on how it will carry out the research.

This study uses a quantitative approach, which describes the relationship between variables to analyze numerical data (numbers) using statistical methods through hypothesis testing.Bogdan and Taylor define qualitative research as research that produces descriptive data in the form of words written or spoken of people and behaviors that can be observed. The method used in this research is descriptive analysis method with quantitative 
approach, ie research which is then processed and analyzed to be concluded. That is, research is research that emphasizes the analysis on secondary data obtained from government agencies.

Definition of descriptive method according Sugiyono (2005, Pg 21), are: a method used to describe or analyze the results of the study but not used for make broader conclusions. As according to Nazir (2005, Pg 63), Descriptive method is a method in researching a group of people, a set of conditions a system of thought or a group at the present time to make a descriptive, picture or painting in a systematic, factual and accurate information on the facts, properties and relationships in the phenomenon under investigation. "While understanding of descriptive analysis method according to Nazir (2005: 71),

Based on the above understanding, the research is carried out by quantitative descriptive method is a form of research that is based on data collected during systematic research of the facts and the properties of the object studied by combining the relationship between variables involved in it, then diinterperetasikan based theories and literature related internal control of payroll and employee salaries. This method aims to provide a fairly clear picture of the problem being investigated. In this research the authors obtained data by using the enclosed questionnaire that has been given a score, where the data will be calculated statistically.

Implementation of observation / as a survey that is critical to get a good description of the light and against a particular issue and in a particular area. Furthermore Mulyana (2001, Pg 83) argues that the survey particularly prevalent digunakam to collect data that is very much about public opinion and the characteristic basic (demographic) of the population, such as gender, religion, occupation, income, hobbies, ownership of property, health, well-being and generally aim to achieve generalization, and others as well as to make a prediction.

\section{Participation}

\section{1. participants}

Participants selected for the study were primary school learners se offerings using secondary data. Secondary data is a source of research data obtained by researchers indirectly through an intermediary medium (obtained and recorded by the other party). Secondary data is generally in the form of evidence, records or historical reports that have been compiled in an archive (documentary data), published and unpublished.

The data used in the form of National Exam Results 2013. Researchers obtain data from the central department of educational assessment (Puspendik) in Jakarta. The results do not include data provision as a whole but is limited by the department.

Secondary data in the form of national examinations results txt files sent by email in the form of dichotomous 1-0. Therefore, researchers turn it into excel for easy analysis based on needs.

\section{Participants Kerteria}

Kerteria participants used by primary schools province-wide offerings with kerteria jumalah districts / cities, districts, and towns / villages.

District / city consists of four counties and four cities of the province of Banten. However, based on the analysis of the area of the four counties and four cities included in kerteria participants in which there are elements of urban and rural districts covering them 
Pandeglang, Lebak district, Tangerang district, county attack, Cilegon city, and attack the city.

\section{3. number of Participants}

Participants generated primary school learners from the Ministry in the form of raw file is still random, to sort according to the analysis of the data supporting the school level researchers in education and culture ministry's website (Kemendikbud) via the website: www.referensi.data.kemendikbud.go.id, The data as follows:

\section{Table 1.1 Data schools}

The Ministry of Education and Culture (Kemendikbud) via the website: www.referensi.data.kemendikbud.go.id,

\begin{tabular}{|c|c|c|}
\hline No. & District / City & Public Alementary Cchool \\
\hline 1 & Kab. Pandeglang & 864 \\
\hline 2 & Kab. lowland & 772 \\
\hline 3 & Kab. Tangerang & 751 \\
\hline 4 & Kab. attack & 706 \\
\hline 5 & City. Cilegon & 219 \\
\hline 6 & City. attack & 3436 \\
\hline
\end{tabular}

Researchers associate with the data from the Central Statistics Agency (BPS) Banten Province. CPM obtained kerteria levels of towns and villages based on the group's most high-level provincial, district / city, district through towns and villages, while kerteria participants are managed as follows:

Table 1.2 Master File village of Banten province in 2013

Central Statistics Agency (BPS) Banten Province

\begin{tabular}{|c|l|c|c|c|c|}
\hline No. & \multicolumn{1}{|c|}{ District / City } & districts & City & Village & Total \\
\hline 1 & Kab. Pandeglang & 35 & 52 & 287 & 339 \\
\hline 2 & Kab. Lowland & 28 & 27 & 318 & 375 \\
\hline 3 & Kab. Tangerang & 29 & 188 & 86 & 274 \\
\hline 4 & Kab. attack & 29 & 72 & 254 & 326 \\
\hline 5 & City. Cilegon & 8 & 39 & 4 & 43 \\
\hline 6 & City. attack & 6 & 37 & 29 & 66 \\
\hline Banten & 135 & 415 & 978 & 1423 \\
\hline
\end{tabular}

\section{Population and Sample}

\section{Population}

Be an overall population of respondents who wanted to investigate. In this study, the population is around the national exam results in public primary schools throughout Banten province with a number of rural and urban schools 3436. With the distribution of respondents on the analysis as follows:

Distribution of survey respondents Tabel1.3 analysis results

\begin{tabular}{|c|l|c|c|c|c|c|c|}
\hline \multirow{2}{*}{ No. } & \multicolumn{2}{|}{ respondents } & \multicolumn{2}{|c|}{ districts } & \multicolumn{2}{c|}{ PopulasiSekolah } & \multicolumn{2}{c|}{ sample School } \\
\cline { 3 - 8 } & & $\begin{array}{c}\text { Village } / \\
\text { Ex }\end{array}$ & School & City & Village & City & Village \\
\hline 1 & Kab. Pandeglang & 35 & 864 & 186 & 678 & 60 & 124 \\
\hline 2 & Kab. lowland & 28 & 772 & 77 & 695 & 25 & 127 \\
\hline 3 & Kab. Tangerang & 29 & 751 & 552 & 199 & 177 & 36 \\
\hline 4 & Kab. attack & 29 & 706 & 172 & 534 & 55 & 97 \\
\hline
\end{tabular}




\begin{tabular}{|c|l|c|c|c|c|c|c|}
\hline 5 & City. Cilegon & 8 & 119 & 112 & 7 & 36 & 1 \\
\hline 6 & City. attack & 6 & 224 & 146 & 78 & 47 & 14 \\
\hline \multirow{2}{*}{ amount } & \multirow{2}{*}{135} & \multirow{2}{*}{3436} & 1245 & 2191 & 400 & 400 \\
\cline { 4 - 8 } & & & \multicolumn{2}{|c|}{3436} & \multicolumn{2}{c|}{800} \\
\hline
\end{tabular}

\section{2. samples}

Sampling is the process of selecting a set of respondents by the reviewer to represent a large collection of the local community or population. the sample is a collection that represents sesebuah population and be a source of information required by the assessment relates the population. The samples used by the school kerteria town / village 800 of the school's 400 town and village solvin 400 based on a calculation formula.

\section{Mechanical sampling}

Ideally, samples should be really depict or represent the actual characteristics of the population. In general, there are two approaches to sample selection methods. Namely nonprobability probability sampling and sampling. In this method, a way of sample selection must be done randomly proportionate stratified random sampling (Sugiono. 2009, $\operatorname{Pg} 82$ )

To determine the random researchers used the help of the internet via the website http://harisaryono.com/utility/acaknomor.php, The site will automatically determine random.

One method used to determine the number of samples is used Slovin formula (Sevilla et. Al., 1960, Pg 182), as follows:

$$
n=\frac{N}{1+N e^{2}}
$$

Where

$n$ : Number of samples

$\mathrm{N}$ : the number of population

e: boundary fault tolerance (error tolerance)

The use of this formula using fault tolerance limits. Fault tolerance limit is expressed as a percentage. With a margin of error of $5 \%$ means it has a $95 \%$ accuracy rate.

\section{Research Instruments}

\section{Instrument}

The research instrument is a tool used to collect data or information useful to answer the research problems. This study did not use the instrument in a primary form but the form of secondary or also called secondary data analysis. Martono (2012, Pg 113) states in a secondary data analysis study researcher mature enough to utilize data obtained at the agency or institution.

In the secondary data obtained grain instrument used in the form of national examinations primary school level, the data for determining the level of item functioning analysis.

In the researchers conducted a secondary data carefully and meticulously authentic as possible to get the data, researchers used the method 


\section{1) Search Manually}

Until now there are many organizations, companies, offices that do not have a complete data base that can be accessed online. Therefore, we still need to do a manual search. Manual search can be difficult if we do not know the method, because the number of available secondary data within an organization, or vice versa due to the lack of existing data. The most efficient way is to look at the book index, bibliography, references and literature appropriate to the issues to be studied. Secondary data from the perspective of the researcher can be classified into two, namely the internal data of data already available in the field; and external data data that can be obtained from various other sources.

a) Internal Location: internal locations can be halved as a source of information that comes from a special database and a common database. Special data base typically contains important information biasanyan company confidential and not available to the public, for example, the data in accounting, finance, hr, sales data and other important information that should only be known by certain people in the company. This type of data will be of much help in detecting and provides a solution to a problem which we will examine in the company. Instead, the public database contains data that is not confidential for the agency and may be known by the public. Data of this type can usually be found in the library office / perusaahaan or stored in a computer that can be accessed in general.

b) Location External: External data can be searched easily because those are stored in a public library, a library of government offices or private sector and universities, central bureau of statistics and trade associations, and usually in a standard form that is easy to read, such as user research, list libraries, encyclopedias, dictionaries, books index, statistical data book and other similar books.

2) Search Online. With the development of Internet technologies then comes a lot of data base that sells a variety of business information as well as non-business. The data base is managed by a number of service companies that provide information and data for the benefit of flying businesses and non-business. The aim is to allow companies, researchers and other users in searching data. Search online provides many benefits for researchers, among them are: a) saving time: because we can do just by sitting in front of computers, b) completeness: through the Internet media portals and certain we can access complete information is available anytime without a limited time c) Suitability: researchers can look for the sources of data and information that fit easily and quickly, d) cost-effective:

\section{Criteria for Evaluating Secondary Data In}

Careful selection of secondary data can be evaluated using the following criteria:

1. The validity period

The data used is the type of data in 2011 in which the accuracy of instruments of national examinations are no longer managed by the central government, but there are new rules through regulations School Operational Procedures submitted to the respective regions.

2. suitability:

Compliance is related to the ability to use the data to answer the problem being studied. According Martono (2012, Pg 121) suitability is determined brdasarkan accuracy in calculation and data processing.

3. Accuracy:

We can determine sources of error that can affect the accuracy of the data can be trusted as a determinant of school quality indicators mapping. According Martono (2012, Pg 
123) there are two categories in predicting accuracy. 1) the accuracy desesuaikan with stability definition and secondary data collection methods. 2) accuracy when dama data from two sources using the same indicators. 3) the accuracy of the use of indicators in a variable in influencing other variables.

4. Cost

In determining the cost of adjusting the value tujua and benefits because the level of accuracy in the analysis of very complex and mutually keterkait.

3 Operations devinisi variable

1. Learners are learners city background in environmental social characteristics of cities that form a group of schools according to how berintraksi based linkage definition to standard stipulation city government.

2. Learners village is learner backgrounds social characteristics of rural environment school groups that formed in accordance with the manner by linkage definition berintraksi villages against government default provisions.

3. Differential item Function is the ability to answer the correct items from different groups but have the same ability to have a different probability, the probability of the difference was caused not because of capability but distinctness factor group.

4. Coat method Haenszel (MH) is a method of detection Differential item Function (DIF) by pairing the two groups using $2 \times 2$ contingency table based on the frequency of correct answers (1) and the wrong answer (0) of the Focus Group and Referring group.

5. Learning of Natural Science is a science of natural phenomena that are set forth in the form of facts, concepts, principles and laws are verified and through a series of activities in the scientific method that involves the application of mathematical reasoning and analysis of data on natural phenomena.

\section{Research procedure}

In determining the research procedures adjust to the approach of quantitative research using survey method with secondary data, while the following steps (Martono 2012, Pg 123-127):

1) formulate the problem

Formulate the problem researchers examined prior to the measurement aspects which include education, aspects covered in this discussion is based on literature review studies and other research studies earlier, so that research can be terusmuskan issues to be analyzed.

2) Specifies the unit of analysis

Formulate operational definition requires analyzing stage from the unit level to the level of sub-units analyzed. To determine the level of the principal sub units must first analyze the existing units. The largest unit in the implementation of this analysis is the provincial level, provincial-level split into district / city level, district level cities in the analysis to the district level, the district level to the village level were analyzed. In order to be the definition of our city schools require village-level data by province, and the level of the village school by province, so we mix between schools in the city and located in the school located in the village.

3) Test and rechecking the availability of data

Validity of the secondary data rates require high accuracy, because the data that we get the data mature form. Data mature normally susceptible to the validity, therefore, 
to control the data checking authentic must berdasrakan on original sources and of course with the appropriate procedures.

4) To study literature

A literature study is an important element in the implementation of the study, because the literature study determines the breadth in the level of thinking and make the results more accurate. In reviewing the literature study researchers first determine the objectives to be achieved in the study. Once the researchers determined the purpose of formulating a working hypothesis to be tested, based on framework created.

5) Collecting data

Search result data obtained based on secondary sources, namely manually and online. The data collected by source and by the analysis unit is connected with the results of the analysis of data that will be the conclusion. The data is the data of the national exam IPA SD 2013 obtained from the Ministry of Education.

6) Secondary data processing

The raw data results of national examinations in the elementary science based relationship with the analysis result data in each unit. The data is processed with statistical methods to be in the know the objectives to be achieved in the study.

7) Present data provide interperetasi

Data komperasi of analysis of each unit with a national exam results were analyzed using the IPA SD coat Haenszel method in the present and diinterperetasi on each grain so that it gets the proper conclusion based on the objectives to be achieved.

8) Prepare reports on research results

The process of preparing a report based on the approval of the supervisor and tested by high step taken, so the results become rich that can be utilized knowledge.

\section{Data analysis}

The data analysis also called data processing and interpretation of data. Data analysis is a review of a series of activities, grouping, systematization, interpretation and verification of data so that a phenomenon has social value, academic and scientific. Activity in the data analysis are: classifying data based on variables and types of respondents, tabulate the data based on the variable and all respondents, shows data for each of the variables studied, perform calculations to answer the formulation of the problem and take measures to test the hypothesis, the last step is not performed.

According Sofian Effendi in his book Research Methods Survey (1987, Pg 231) is simplifying the data in a form that is easier to read and diinterperetasi. The data analysis is intended to understand what lies behind all of the data, classify it, distill them into a compact and easy to understand, and find common patterns that arise from these data.

Analysis on research using quantitative analysis. Before performing a quantitative analysis based on those first researchers examined the qualitative analysis study was conducted based on a literature review according to the aspect of material, construction, and language, so that researchers can provide a framework formulation and formulation of the problem based on the review. The analysis used in this peneltianian using quantitative analysis method haeszel coat.

coat Haenszel statistical methods used to determine grain contracted differential item function (DIF) in the IPA national exam test device SD with the number of about forty items. In this analysis, researchers will test the hypothesis formulated based on the study of theory and previous research literature. 
In the process of analyzing the statistical data are often used because it is one of the statistical function is to simplify the data. The process of data analysis is not just to be here. Analysis of the data has not been able to answer the research questions. After the data is analyzed and the information obtained is more simple, the analysis results continue to be diinterpetasi to seek a broader meaning and impilkasi results of the analysis and answer the hypothesis.

Statistical hypothesis as follows

$$
\begin{array}{ll}
\text { HO } & \text { Sig } M H<\alpha \\
\text { Ha } & \text { Sig } M H \geq \alpha
\end{array}
$$

With kerteria test as follows:

If the value Sig $\mathrm{MH}<\alpha$ : detected significant DIF then declared H0 In Decline. Sig value $\geq$ $\alpha \mathrm{MH}$ : undetectable significant DIF then declared H0 Di Accept

The coat interperetasi Haenszel analysis using SPSS 21 for predicting the otherness of the function items as follows:

Differential Item Function(DIF) based on differences in urban and rural areas by using a 95\% confidence level with a margin of error (alpha 0,05). With kerteria ratings Differential Item Function (DIF): sig $<\alpha$ then infected grain Differential Item Function (DIF) and sig $\geq \alpha$ those items not affected by Differential Item Function (DIF)

Tendency analysis of urban and rural areas to the city as the reference group and the village as a focus group. With kerteria trend assessment: when the value in positive $\mathrm{MH}$ estimate the trend lies in the city, when the value in negative $\mathrm{MH}$ estimate the trend lies in the village.

\section{1. finding}

\section{RESULTS}

preparing first data for materials analysis. At the analysis stage need ditentukanya analysis unit to facilitate the work and to the point, such as in determining urban and rural schools. It should we classify based unit.

The level of organization in the formulation stage of analysis included in the provincial, district / city, district, and village / village both the school level and the level of government agencies, because of two things will dikomparasikan forming which schools are categorized in city schools and rural schools.

Based on the theory can be said city schools because there is a city boy who mutually berintraksi one another and form habits based on where tingal kebradaan school adapted to the location of the town or village government areas. Here's how the chart analysis of schools, and government agencies towns and villages based on those units of analysis. 
Figure 1.1

Distribution Data Elementary School

District / city level

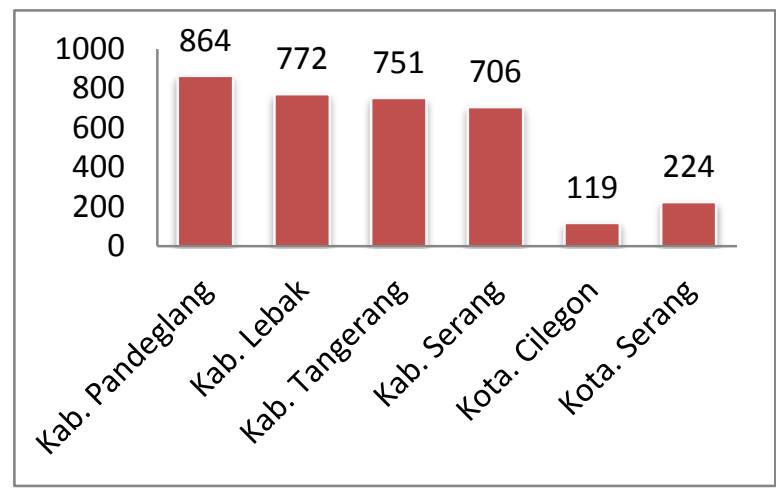

Figure 1.2

Data Distribution Region

District / city level

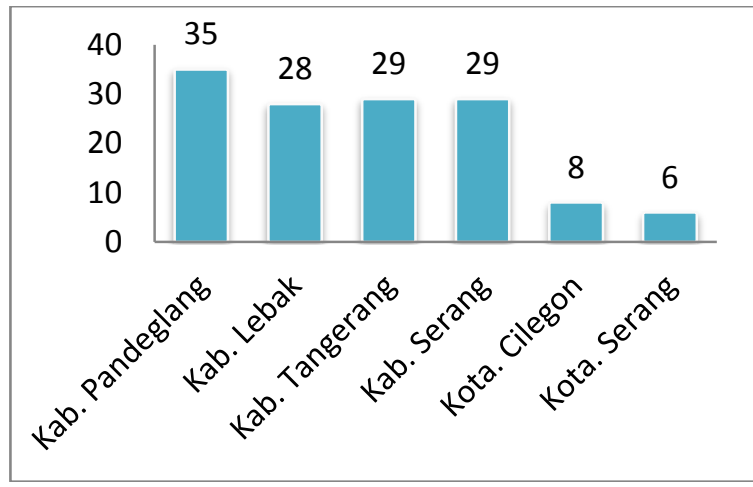

The picture above is a graph of data generated data results from the ministry of education and culture. Level analysis Banten province by fractional analysis covering four counties and four cities with a number of schools as follows: 1) kab.Pandeglang SDN number 867. 2) kab.lebak SDN number 774. 3) kab.tangerang SDN number 759. 4) districts. attack number 710. 5 SDN) SDN kab.cilegon number 343. 6) kab.serang SDN number 224. this school data that will connect with the data villages to get the number of urban and rural schools.

The picture above is a graph of data generated result data from the BPS. Level analysis Banten province by fractional analysis covering four counties and four cities with a number of schools as follows: 1) kab.Pandeglang Village number 35. 2) kab.lebak Village number 28. 3) kab.tangerang village number 29.4) districts. attack village number 29. 5) kota.cilegon village number 8. 6) kota.serang number of Sub 6. Data of this school that will connect with the data villages to get the number of urban and rural schools. 


\section{Figure 1.3}

Data distribution areas of the city

Municipal / district level

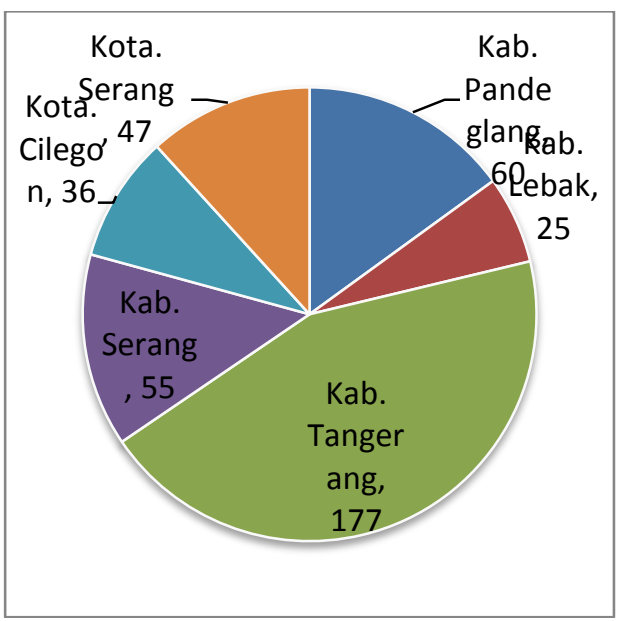

The picture above is an analysis of data per village school by the district / city based on the analysis unit districts / cities, districts, until the village resulting in the data urban city district / city level

Figure 1.4

Data Distribution village area

Municipal / district level

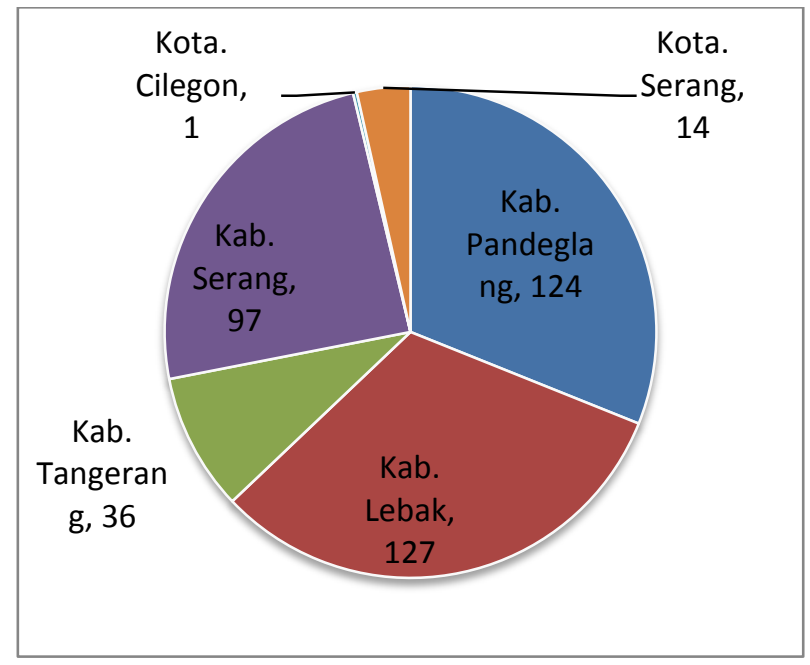

The picture above is an analysis of data per village government by the district / city based on the analysis unit of the district / city, district, village to village to generate data city district / city level 
Figure 1.5

comparison sample

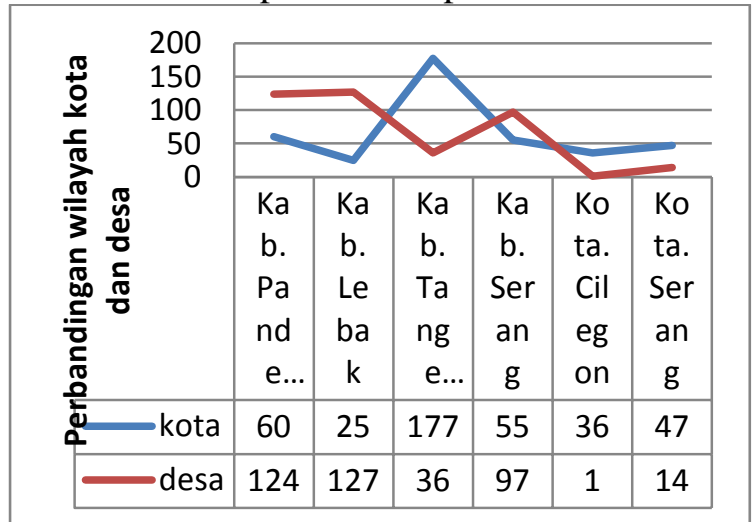

Images on the final outcome of a connection with the data analysis unit of the village government school / village. By analysis of the district / city, district, village / village. So it gets the results of the city schools and rural schools.

Based on the sampling of each data obtained from each institution both educational assessment department, the Central Statistics Agency (BPS) and Kemendikbud, so the researchers collected data by sampling each group penalikan urban and rural areas amounted to 800 respondents. 400 respondents city schools and 400 rural schools as well as at each school is taken of the students national examination results, and therefore the data can be analyzed by using SPSS sofwere 21 .

To test the item is located DIF or not, the researchers tested the hypothesis by using the following formula:

$$
\begin{array}{ll}
\text { H0 } & \text { Sig MH }<\alpha(0: 05) \\
\text { Ha } & \text { Sig MH } \geq \alpha(0: 05)
\end{array}
$$

With kerteria test as follows:

If the value Sig MH $<\alpha$ : detected significant DIF then declared H0 In Decline. Sig value $\geq$ $\alpha \mathrm{MH}$ : undetectable significant DIF then declared H0 Di Accept follows:

So, from the analysis of each item, amounting to 40 eggs can be concluded as

\section{(1) Grain tests based defferential item functioning (DIF)}

Based on statistical analysis with Mantel Haenszel method can be inferred that the DIF infected grains are grains $38,33,27,26,25,23,21,19,15,9,5,1$. Because of significant value in the table is smaller than the value $\mathrm{MH}$ alfa then this item contracted DIF

(2) Item test students' tendency towards towns and villages

The trend of the gain in statistical analysis using Mantel Haenszel can be concluded that the grains tend to urban areas as much as 5 grains such as $1,5,15,19,38$, and grains tend to rural areas as much as 7 grains such as 9, 21, 23, 25, 26, 27, 33 . 


\section{Discussion}

Analysis of differential item function (DIF) using statistical analysis using the Mantel Haenszel test device IPA Elementary school national exam to differences in urban and rural schools can be summarized in the tables attached hereto as:

Based on the literature review in Chapter II covering the discussion relating to differential item function (DIF) is the correct answer capability of an item from a different group but have the same ability to have a different probability, the probability of the difference was caused not because of capability but distinctness factor group.

The group behind pembahsan on the analysis of the group of urban and rural areas. City groups are learners backgrounds city neighborhood social characteristics that make up the group schools according to how berintraksi based linkages standard definition to the provisions of the city government. While the village is a group of learners background in environmental social characteristics that make up the village school groups according to how berintraksi based linkage definition villages against government default provisions.

Groups of urban and rural areas which are formed by the interaction of the units of primary education affects learning outcomes in the subjects tested, it is associated with the process of learning science is able to create learning directly related to real learning process on the surrounding environment, so that in assessing national examinations made trends point to one group. National exam test device in 2013, amounting to 40 grains analyzed by different groups of towns and villages, by analyzing the results of national examinations in 2013 using statistical methods Haenszel coat.

Coat method Haenszel (MH) is a method of detection of DIF by pairing the two groups (Holland, 1993: 143). The initial data used are 2 × 2 contingency tables $\mathrm{MH}$ procedure is a method of using the chi square full table $2 \times 2$ on the frequency of correct answers (1) and the wrong answer (0) of the Focus Group and Referring group. There are two data that can be paired, ie the number of correct answers and the wrong answer or the score of a particular group, for example, the average score. Berdsasarkan research studies that discuss the dif from multiple devices group differences become domain so that the analysis on the test device is always a tendency to bias caused.

Therefore, based on a literature review and a review of previous studies, the researchers predict that the hypothesis is tercantumkan There are three items or more detectable Differential Item Function based on the analysis of differences in urban and rural areas in the National Examination test devices IPA Elementary School

Analysis defferential item functioning (DIF) based on differences in urban and rural areas in the National Examination IPA SD data card using Haenzel coat analysis in get the following conclusion:

\section{Table 1.4}

Analysis of Differential Item Function (DIF)

\begin{tabular}{|c|c|c|c|c|}
\hline No. & MH & Sig & DIF & refraction \\
\hline Butir1 & 1,979 & 0043 & $*$ & CITY \\
\hline Butir2 & 0466 & 0086 & & \\
\hline Butir3 & -0458 & 0081 & & \\
\hline Butir4 & 0417 & 0237 & & \\
\hline Butir5 & 0850 & 0001 & $*$ & CITY \\
\hline Butir6 & -0053 & 0829 & & \\
\hline
\end{tabular}




\begin{tabular}{|l|c|c|c|c|}
\hline Butir7 & 0341 & 0259 & & \\
\hline Butir8 & -0385 & 0069 & & \\
\hline Butir9 & -0432 & 0013 & $*$ & VILLAGE \\
\hline Butir10 & -0071 & 0698 & & \\
\hline Butir11 & 0419 & 0051 & & \\
\hline Butir12 & 0288 & 0101 & & \\
\hline Butir13 & -0125 & 0504 & & \\
\hline Butir14 & -0.01 & 0995 & & \\
\hline Butir15 & 0638 & 0001 & $*$ & CITY \\
\hline Butir16 & -0100 & 0615 & & \\
\hline Butir17 & -1.00 & 0615 & & \\
\hline Butir18 & 0114 & 0586 & & \\
\hline Butir19 & 0472 & 0024 & $*$ & CITY \\
\hline Butir20 & 0527 & 0087 & & \\
\hline Butir21 & -0461 & 0026 & $*$ & VILLAGE \\
\hline Butir22 & -0199 & 0334 & & \\
\hline Butir23 & -0412 & 0030 & $*$ & VILLAGE \\
\hline Butir24 & -0233 & 0278 & & \\
\hline Butir25 & -0454 & 0033 & $*$ & VILLAGE \\
\hline Butir26 & -0454 & 0033 & $*$ & VILLAGE \\
\hline Butir27 & -0508 & 0003 & $*$ & VILLAGE \\
\hline Butir28 & 0194 & 0292 & & \\
\hline Butir29 & -0236 & 0227 & & \\
\hline Butir30 & -0236 & 0227 & & \\
\hline Butir31 & 0379 & 0242 & & \\
\hline Butir32 & 0379 & 0242 & & \\
\hline Butir33 & -0721 & 0000 & $*$ & VILLAGE \\
\hline Butir34 & 0247 & 0440 & & \\
\hline Butir35 & -0248 & 0185 & & \\
\hline Butir36 & -0248 & 0185 & & \\
\hline Butir37 & 0216 & 0391 & & \\
\hline Butir38 & 0674 & 0023 & $*$ & CITY \\
\hline Butir39 & 0192 & 0281 & & \\
\hline Butir40 & 0192 & 0281 & & \\
\hline & & & & \\
\hline
\end{tabular}

So it can be concluded based on the analysis of differential item function (DIF) device test Exam National Science Elementary School based on differences in urban and rural areas using the coat Haenszel by the number of about 40 grains of grains were detected differential item function (DIF) totaled 12 of which item 33, 27, 26, 25, 23, 21, 19, 15, 9, 5,1 . the items tend to the town area amounts to 5 eggs are $1,5,15,19,38$, and grains tend to rural areas totaled 7 items ie $9,21,23,25,26,27,33$. the items were not detected differential item function (DIF) accounted for 28 of them $2,3,4,6,7,8,10,11,12,13,14$, $15,16,17,18,20,22,24,28,29,30,31,32,34,35,36,37,39$, and 40.This proves detected differential item function (DIF) in point device SD IPA national exam in 2013 


\section{CONCLUSION}

Analysis of differential item function (DIF) at the National Examination test devices based on different IPA Elementary urban and rural areas by using coat Haenszel method with the amount of about 40 grains. Items detected differential item function (DIF) totaled 12 of which grain $38,33,27,26,25,23,21,19,15,9,5,1$. The items tend to the town area amounts to 5 eggs are $1,5,15,19,38$, and grains tend to rural areas amounted to 7 grains are $9,21,23,25,26,27,33$. the items were not detected differential item function (DIF) accounted for 28 of them $2,3,4,6,7,8,10,11,12,13,14,15,16,17,18,20,22,24,28$, $29,30,31,32,34,35,36,37,39$, and 40

Table 1.5 Gruping Grain differential item function (DIF)

\begin{tabular}{|l|l|l|l|l|}
\hline \multicolumn{1}{|c|}{ DIF } & Tot & \multicolumn{1}{|c|}{ grain } & Tot & \multicolumn{1}{|c|}{ Trend } \\
\hline Item DIF & 12 & $38,33,27,26,25,23$, & 5 & $\begin{array}{l}\text { Item City } \\
1,5,15,19,38,\end{array}$ \\
\cline { 3 - 4 } & & $21,19,15,9,5,1$. & & grain Village \\
\cline { 3 - 4 } & & & 7 & $9,21,23,25,26,27,33$. \\
\hline Grain Non DIF & 28 & $2,3,4,6,7,8,10,11$, & & \\
& & $12,13,14,15,16,17$, & & \\
& & $18,20,22,24,28,29$, & & \\
& & $30,31,32,34,35,36$, & & \\
& & 37,39, and 40. & & \\
\hline
\end{tabular}

From the above data it can be concluded that there is a differential item function (DIF) at the IPA National Examination test device SD amounted to 12 grains of the total items on the test device as much as 40 grains. The items affected by the differential item function (DIF) on the test device twelve grains and grains that are not affected by differential item function (DIF) totaling 28 items. With the trend of grain to areas of the city amounted to 5 grains and grains tend to rural areas amounted to 7 items.

\section{REFERENCES}

Martono, Nanang. 2012. Metode Penelitian Kuantitatif. Jakarta: PT Raya Grafindo Persada.

Mulyana, Deddy. 2001. Metode Penelitian Kualitatif. Bandung: Remaja Rosdakarya.

Nazir, Moh. 2005. Metode penelitian.Bogor : Ghalia Indonesia.

Osterlind, Steven, J. (1983). Test Item Bias. California: Sage Publication

PERMENDIKNAS No.20 Tahun 2007 tentang Penilaian Pendidikan

Sevilla, C. G.et. al. 1960. Research Methods. Quezon City: Rex Printing. Company.

Singarimbun, Masri dan Sofian Effendi, 1987, Metode Penelitian Survai, LP3ES, Yogyakarta

Sugiyono, (2005). Statistik Untuk Penelitian. Bandung : Alfabeta 
Sugiyono, (2009). Metode Penelitian Kuantitatif Kualitatif dan $R \& D$. Bandung : Alfabeta www.referensi.data.kemendikbud.go.id.

http://harisaryono.com/utility/acaknomor.php. 